\title{
AL. Award Lectures
}

\section{AL1 \\ Harnessing the non-heme $\mathrm{Fe}(\mathrm{IV})$-oxo unit for diverse reactivities \\ J. Martin Bollinger Jr, and Carsten Krebs}

Department of Chemistry and Department of Biochemistry and Molecular Biology, Penn State University, University Park, PA 16802, USA.jmb21@psu.edu

Mononuclear non-heme iron oxidases and oxygenases play essential roles in myriad biological processes, including biosynthesis of natural products, control of oxygen homeostasis, and regulation of transcription [1]. Over the past 6 years, we and our coworkers have characterized the key Fe(IV)-oxo (ferryl) intermediates in several members of this important enzyme family [2]. These complexes are sufficiently potent to homolyze methyl $\mathrm{C}-\mathrm{H}$ bonds but are harnessed within proteins possessing both more reactive aliphatic centers and aromatic residues potentially capable of electron transfer to the ferryl species. Control of this potent chemistry involves proper timing of ferryl formation by "substrate triggering," a marked activation of the $\mathrm{Fe}$ (II) cofactor toward reaction with $\mathrm{O}_{2}$ caused by binding of the substrate $[3,4]$. However, subversion of this control mechanism by use of substrates with stronger or inappropriately positioned $\mathrm{C}-\mathrm{H}$ bonds has revealed the intermediates to be remarkably stable [2], in one case for hours at $0{ }^{\circ} \mathrm{C}$ ! [5]. Moreover, after abstraction of hydrogen from the substrate, resultant $\mathrm{Fe}(\mathrm{III})-\mathrm{OH}$ intermediates can "rebound" to the substrate radical either the hydroxyl group or a ciscoordinated sulfur (as in isopenicillin $N$ synthase) or halogen (as in the aliphatic halogenases) [6]. Our work seeks to explain how the enzymes protect the ferryl complexes to such a remarkable extent and how they dictate the decay pathway to achieve such exquisite reaction specificity.

\section{References}

1. Hausinger RP (2004) Crit Rev Biochem Mol Biol 39:21-68

2. Krebs C, Galonić Fujimori D, Walsh CT, Bollinger JM Jr (2007) Acc Chem Res 40:484-492

3. Solomon EI, Brunold TC, Davis MI, Kemsley JN, Lee S-K, Lehnert N, Neese F, Skulan AJ, Yang Y-S, Zhou (2000) J Chem Rev 100:235-349

4. Costas M, Mehn MP, Jensen MP, Que L Jr (2004) Chem Rev 104:939-986

5. Matthews ML, Krest CM, Barr EW, Vaillancourt FH, Walsh CT, Green MT, Krebs C, Bollinger JM Jr (2009) Biochemistry. doi:10.1021/bi900109z

6. Galonić DP, Barr EW, Walsh CT, Bollinger JM Jr, Krebs C (2007)

Nat Chem Biol 3:113-116
AL2

Proteins, metals, spectra and quanta: a powerful combination

Frank Neese ${ }^{1,2}$

${ }^{1}$ Universität Bonn, 53115 Bonn, Germany.

${ }^{2}$ MPI für Bioanorganische Chemie, 45470 Mülheim an der Ruhr, Germany.neese@thch.uni-bonn.de

Metalloenzymes catalyze a wide variety of reactions under mild chemical conditions that can hardly be achieved in the laboratory. Understanding these reactions on a molecular level is a prime goal of bioinorganic research. Much of what we know today about enzyme active sites originates from the application of advanced spectroscopic methods. In particular for short lived intermediates spectroscopy is the only source of structural knowledge. In order to develop the full information content of the observed spectra it seems indispensable to resort to quantum chemical calculations. Our group has actively developed methods to predict various kinds of spectroscopic properties of enzyme active sites including EPR, Mössbauer, Absorption, CD, MCD, XAS, NRVS and resonance Raman spectroscopies. These methods are widely employed in (bio)inorganic research and are implemented in the freely available ORCA program package (http://www.thch.uni-bonn.de/tc/orca/). The lecture will present recent progress in combining DFT and ab initio methods with QM/ MM approaches in order to obtain insight into the geometric and electronic structures of metalloenzymes and model systems.

\section{References}

1. Neese F (2009) Calculation of molecular spectra and molecular properties with density functional theory: from fundamental theory to exchange coupling. Coord Chem Rev 253:526

2. Pantazis D, Orio M, Petrenko T, Messinger J, Lubitz W, Neese F (2009) A new quantum chemical approach to the magnetic properties of oligonuclear transition metal clusters: Application to a model for the tetranuclear manganese cluster of photosystem II. Chem Eur J (ASAP)

3. Sinnecker S, Svensen N, Barr EW, Ye S, Bollinger JM, Neese F, Krebs C (2007) Spectroscopic and theoretical evaluation of the structure of the high-spin $\mathrm{Fe}(\mathrm{IV})$-oxo intermediates in taurine: $\alpha$-ketoglutarate dioxygenase from Escherichia coli and its His99Ala ligand variant. J Am Chem Soc 129:6168 